\title{
ABSTRACTS*
}

\section{Competence and Resolution of Issues in English for Specific Purposes Instructional Materials Preparation}

\author{
Nilbert L. Magno \\ Department of Education-Cadiz City Schools Division, Philippines \\ nilbertlimmagno@gmail.com \\ https://orcid.org/0000-0002-8615-8014
}

\begin{abstract}
This descriptive-comparative research determined the teachers' level of competence and extent of the resolution of issues in the preparation of English for Specific Purposes instructional materials in terms of availability of facilities for authenticity, training of teachers, and curricular decision. A researcher-made instrument was employed to gather data from purposively sampled 41 English Teachers in a public senior high school. Using the frequency and percentage, mean, t-test, and one-way ANOVA in analyzing the results, findings revealed that the teachers' level of competence, when taken as a whole and grouped according to demographic variables, has a high level. The high level of competence can be attributed to teachers' training workshops. Meanwhile, the extent of the resolution of issues is moderate. The findings signify that stakeholders involved should always initiate certain programs for the continuous provision of instructional materials and design training-workshops to improve the level of competence and preparedness of the English teachers.
\end{abstract}

Keywords: Language Education, Competence, Resolution of Issues, English for Specific Purposes, Instructional Materials Preparation, Descriptive, Comparative, Negros Occidental, Philippines.

\footnotetext{
* The full papers of these abstracts are available at Fray Luis de Leon Library of the University of Negros Occidental-Recoletos, Bacolod City Philippines. The may also be obtained by contacting the respective authors through their email addresses.
} 